\title{
Comparative Study of Culture in Kurdish and Farsi
}

\section{Proverbs}

\author{
Hadi Yousefi \\ Assistant professor of Persian language and Literature, Department of Humanities, \\ Payame-e Noor University, \\ Tehran, Iran \\ E-mail: dr.h.yousefi80@gmail.com
}

Accepted: October 03, 2012 Published: November 13, 2012

Doi:10.5296/ijld.v2i6.2679

URL: http://dx.doi.org/10.5296/ijld.v2i6.2679

\begin{abstract}
:
Proverbs are considered as part of folklore or public literature and one of important cultural treasures. Hence, discussing and studying proverbs can make us familiar with cultural aspects, value and norms of the owners of those proverbs. In this study Kurdish and Farsi proverbs are investigated based on cultural components and its species are presented and classified based on the same components.

The present study shows that Kurdish and Farsi proverbs have spoken of two categories of values and norms, and anti-values and abnormalities, first, positive values and norms such as encouraging to truthfulness, effort, patience and tolerance, pragmatic, wise, etc; and second, negative values and in other words anti-values and abnormal action that they have been blame such as lying, avarice, cruelty, etc; also based on Malinowski's theory, the three individual, social and combined functions are conceivable
\end{abstract}

Keywords: Culture, Value, Norm, Anti-Value, Kurdish proverbs, Farsi proverbs, etc.

\section{Introduction}

Studying and verifying nation's culture-especially people who have lived together for yearsmake us familiar with their cultural similarities and anisotropies one of the most controversial issues in the field of culture, that is very important and besides having significant function is society, has been manifested in the literature as well and somehow influences literature are proverbs; elements that are combined with literature and present its specific meaning in a literary form to the address and thus have done the style of message transmission beautifully. Therefore, studying proverbs from the two cultural and literary angles seems necessary; because proverbs can be investigated in the cultural field since they carry moral dos and don'ts messages and more correctly speak of values and norms; and due to their incidence in terms of literary style and placing among the folklore of nations have a status in the literature as well. The first part of the present study investigates and compares semantics and moral teachings and in other words values and norms, and on the other side anti-values and abnormalities raised in Kurdish and Farsi proverbs; that so far have not been considered in the conducted studies, but the significant point in this issue is the closely linked and sometimes intertwined and complex relationship between culture and literature that makes 
determining the exact boundaries of the two largely impossible. But despite this issue, tracking and exploring in this field can makes us familiar with delicate and very sensitive relationship between culture and literature, that its instance as cultural components-that are mentioned in definitions, are values and norms of every society that somehow reflect in the literature of that nation. In this study, the author stepped in line with this and aims to examine and explain the relationship between culture and literature from this angle.

Needless to say that, high application of proverbs in daily conversations and attraction of the topic lead some individuals to conduct studies and researches in this field and have caused them to write several book and articles on this subject. Some books merely collected Kurdish proverbs and have great contributions in terms of providing the literature treasury of Iran; for which the following books can be mentioned:

The first group, books of Kurdish proverbs: predecessors aphorism (ancient advice) written by mohammad Khal that has been published in Baghdad for the second time./ Kurdish proverbs and sayings written by Ghader Fattahi Ghazi that its first volume was published in 1364 and the second one in 1375 in Tabriz University publication. Gwara-i Kordawari written by the late Dr. Ali Rokhzady adorned in 1328 by armaments and about four thousands proverbs have been collected in this book.

The second group, books of Farsi proverbs: proverbs and sayings, Ali Akbar Dehkhoda, Tehran, Amir Kabir publications, 1390/ a comprehensive dictionary of proverbs and sayings, Abdolhossein Faghihi, Abolfazl Rezaei, Alireza Ostovari (editor), Tehran 1390/ dictionary of 20 thousands proverbs, sayings and expressions, Mehdi Mohaghegh-Sadegh Rezaei, Tehran, International publications of Dialogue among Civilizations, 1384/ proverbs and allegory in Iranian literature and culture, Hossein Ali Khoda Karami, Tehran, Dastan, 1387/ great dictionary of Persian proverbs (Persian proverbs of Iranian tribes and Persian-speaking countries), Hasan Zolfaghari, Tehran, Moein, 1389

Third group, comparative books: some books have turned to the issue of matching Kurdish proverbs with proverbs of other nations especially Farsi proverbs among which the book of a collection of various nations proverbs (Kurdish-Farsi) written by Mohammad Kazem Mafakheri (Grdmyrany) in 1377 which was published in Tehran by Saba publications. In this book in addition to Kurdish proverbs and their Persian equivalents, English, German, Spanish, etc proverbs have been mentioned at the end of the book.

Another book written in the same field is of Comparative study of Kurdish and Farsi proverbs written by Ahmad Parsa; and among them are books of Farsi-German proverbs and saying, written by Alireza Amoozandeh, Tehran, Alborz publications, 1386/ dictionary of FarsiRussian proverbs and sayings, Safar Ali Farsadmanesh, Loodmila Pejou, Tehran, institute of Tehran University Publications and printing, 1384.

Despite writing the aforementioned books, the issue that is not covered so far and performing it seem essential is examining proverbs from the angle of cultural components and especially values and norms which is the discussed subject of this paper. In these lines, first some definitions of culture, value and norm are presented, then instances of values and norms, and their opposites i.e. anti-values and abnormalities in Kurdish proverbs are provided. Also the proverbs will be studied and classified in terms of its personal and social functions.

\section{Culture:}

Culture has been used in dictionary books as literature, knowledge, science and wisdom (Moein, 1379, under culture). But its particular meaning of culture-that is mentioned in sociology books, etc-has different and non-comprehensive definitions; because, acknowledged by scholars of sociology science and aware of cultural issues, providing a comprehensive and barrier definition for culture is not possible. But despite the problem of 
definition, some definition which include various aspects of culture have been provided by sociologists: Taylor uses culture as "knowledge, beliefs, arts, ethics, customs and other social results of human"; and Malinowski knew it as "material culture, values, norms and actual behaviors"; while Radcliff Brown believed that culture" is standardized forms of behavior, thoughts and feelings" (Danny Koosh, 1381:1).

The book "Culture and Pseudo-Culture" writes: "culture is "manifestation" and "abstract" of scientific, theoretical, rational and emotional receiving and understandings of a nation and lacks insufficiencies that may be in rituals and beliefs; and since culture is fruit of the best talents, ideas and behaviors of a nation, always the most prominent people of a nation are its indicative, fosterer and narrator (Islami Nadushan, 1371:36).

The definitions presented in previous lines especially that of Taylor and Malinowski, two or three issues-that are the subject of this article-have been introduced as culture, including: value and norm that each has its particular definition, that are pointed in order and finally the relationship between Kurdish proverbs and sayings with the proposed concepts are described.

\section{Proverb:}

The word proverb means peer, similar and like, and the so-called literary men, it's a particular literature that is called in Farsi story (Dehkhoda, under proverb word). Shakoorzadeh Boluri has mentioned in the definition of proverb: "short, useful and pleasant words that each has a deep and subtle thought or a delicate and elegant reminder, and has been accepted over time due to simplicity, eloquent and thought depth and eventually is used by public and specific people and has got the name of proverb." (Shakoorizadeh Boluri, 1380: 8).

"proverb is a concise, useful and meaningful word that Suddenly was exudates from the tongue of a rhetorician and awake-hearted person that in fact in which he expressed the inner conscience of others, and then because well-known to all and went from mouth to mouth" (Fattahi Ghazi, 1364:2); and finally is given that: "proverb is a short, expressive and often rhythmic that has found fame as an allegorical metaphor for proof or applying advice without any verbal change" (Parsa, 1387:15).

\section{Value:}

The two concepts of value and norm are of major and essential concepts of sociology. Value has been defined in sociology as good or bad, proper and desirable, and improper and undesirable for a person or group (Gidenz, 1373: 162). Bruce Coen write in the book Principles of Sociology: values are deep-rooted feelings that society members share in it; these values determine actions and behaviors of society. Every society highly prizes for family life, preserving religions standards, observing parents rights, preserving courtesy and respecting adults; although these values have different interpretations and is prevalent widely and deeply in every society (Coen, 1369: 61).

Gay Roche influenced by Durkheim and Parsons knows values as symbolic base of action, and writes: value is a way of being or acting that a person or public knows as ideal, and makes persons or behaviors attributed to that marked and optimal (Roche, 1367: 76-77). Olson knows values a set of basic thoughts to what is favored that are manifestation of the deepest shared feelings of world in the society (Chalabi, 1375: 60).

\section{Norm:}

Norm in terms of sociology is a behavioral pattern that gradually forms between member of a group and society and not respected, the person is faced with a punishment, or dos and don'ts 
that the person in group or society is bound to do it, otherwise will be faced with penalties (Rafee pour, 1378: 55-56).

\section{The Relationship between Value, Norm and Behavior:}

Values set the ground for the formation of norms, and norms are explicit and imperative aspect of values. Values are components of beliefs. Norms are rooted in values. Values are regulation of behavior. Behaviors are acting in accordance with regulations (norms). Therefore, in summary the following relationship is established between values, norms and behaviors. For example, worship (value), human must worship God (norm), the individual prays (behavior) (Amiri, 1385: 26).

Proverbs as a recipe for doing good behavior and acts include positive recommendations and sometimes prohibiting from doing an act. In this section, first instances of that category of proverbs are presented that recommends good behaviors; then some examples of the second category that include prohibiting from anti-values and abnormalities are provided. The diagram of values and norms and their opponents i.e. anti-values and abnormalities can be drawn as follows:

\section{First Category: Values}

Examining Farsi and Kurdish proverbs show that some of them contain and propagandist of values. Values such as: "ingenuity", "visionary", "Self-esteem" and etc.

The following examples are instances of those values and in the presented examples first Kurdish proverbs are mentioned and then its equivalent proverbs among Farsi proverbs:

Patience and tolerance: “men's pot is boiled forty years and suddenly overflows" (Rokhzady, 1382: 269, No. 5) = who has not forbearance has devil and brute (Shakoorzadeh Boluri, 1380: 1014).

Wisdom: "understanding is more enjoyable than eating rice" (Rokhzady, 1382: 158, No.5) = a wise man does not fall in a hole twice (Shakoorizadeh Boluri, 1380: 23).

Courageous: "does not escape the attack of thousands ride" (Rokhzady, 1382: 110, No.23) = "I'm not afraid of rain since I fell in a sea" (Shakoorzadeh Boluri, 1380: 936).

Effort: "chicken makes the place of its resting ready even for a night" (Rokhzady, 1382: 359, No.77) = If you seek treasure, suffer for your demand (Shakoorzadeh, Boluri, 1380: 837).

Temperance / moderation: do something for a blessing, not burn skewer nor roast" (Rokhzady, 1382: 281, No.8) man should bite to the size of his mouth (Shakoorzadeh Boluri, 1380: 15).

\section{Norms:}

The other category of proverbs contains dos and don'ts or behavioral norms in line with inviting members of society to good deeds. The following examples can be cited as some of these cases:

Contentment: "be gratified with your syrup and don't look at the honey of people (don't stare)" (Rokhzady, 1382: 86: No. 171) = comfort is in contentment and greatness is in mysticism (Shakoorzadeh Boluri, 1380: 563).

Gratitude: if you eat anyone's bread you should utter "praise" for him" (Rokhzady, 1382: 377, No. 47) = Be grateful to deserve goodness (Shakoorzadeh Boluri, 1380: 622).

On time training: "one should snap the cow's tail when it's a calf" (Rokhzady, 1382: 310, No.1) $=$ the plant should be made straight when it is wet (Shakoorzadeh Boluri, 1380: 952).

Caution: "close your door and don't accuse the neighbor's dog of stealing "(Rokhzady, 1382: 184, No.43) $=$ one must have eyes behind his head as well (Shakoorzadeh, 1380: 15). 


\section{Second Category: Anti-Values:}

This category of proverbs contains anti-values. Needless to say that, this group of proverbs is such that society members are prohibited from tendency toward them. Some examples of this category can be named as follows:

Cruelty: Everything will tear if gets narrow but cruelty in thickness (when increases) (Rokhzady, 1382: 315, No.33) = the house which is builds with cruelty, dogs will play around (Shakoorzadeh Boluri, 1380: 433).

Lying: "lie is still in the mouth but limps" (Rokhzady, 1382: 186, No.53) = a lying face doesn't have luster (Shakoorzadeh Boluri, 1380: 939).

Parasite: "patch without obtrusive" (Rokhzady, 1382: 103, No.287) = a sponger looks for a dead donkey to pluck its stud (Shakoorzadeh Boluri, 1380: 26).

Avarice: "he gives the poured oil into his father's charity" (Rokhzady, 1382: 216, No.18) = the miser rub the bread to the back of the glass (Shakoorzadeh Boluri, 1380: 20).

Misfortune: "when the fortune is tilted, cottage (semi-stiffen cheese) breaks teeth "(Rokhzady, 1382: 395, No.35) = the rock comes to the lame leg (Shakoorzadeh Boluri, 1380: 988).

\section{Abnormalities:}

This group includes don'ts actions which the person should avoid, including:

Rush: "don't marry in haste, so not to be regretful gently" (Rokhzady, 1382: 81, No.136) = a nervous person puts on two feet in one trousers leg (Shakoorzadeh Boluri, 1380: 21).

Opportunism: "he is fishing in a muddy water" (Rokhzady, 1382: 329, No.29) = anyone who fells, all will roll the wall on him (Shakoorzadeh Boluri, 1380: 1006)

Bad companion: don't sit next to a black pot to not get black (Rokhzady, 1382: 326, No.5) = don't be accompanied with evil-name people (Shakoorzadeh Boluri, 1380: 206).

Nosy: "he is looking for his peas and cotyledon" (Rokhzady, 1382: 77. No.109) = why do you interfere in others' work, eat a bread and ride your donkey (Shakoorzadeh Boluri, 1380: 404).

\section{Proverb Function:}

Malinowski, English anthropologist (1884-1942) believes in his function oriented theory that every culture, every tradition, every object, every opinion and every belief has a vital function; a task that should be performed and each constitutes an irreplaceable part of the whole organic. He plans the theory of "needs" for explaining practical quality of different culture. In his opinion, the function of elements of a culture is satisfying basic human needs. He borrows his model from natural sciences and recalls that humans constitute as species of animal. The individual feels a number of physiological needs (nutrition, reproduction, selfpreservation, etc.) that specify basic requirements. Culture exactly presents functional answers to these requirements (Danny Koosh, 1381: 56-58). According to the needs theory of Malinowski-that was referred to in previous lines-it can be concluded that proverbs and their long years of life in the context and reticular of human life is the result of need and continuation of this need during times. That has continued until now and will continue in future as well. One of society needs-to which proverbs respond-is cultural and ethical need in the domain of personal and social issues. This request is concern of gentlefolk and public, because its consequences directly refer to the collective life. Proverbs on the one hand flaunt cultural enrichment of a society with their long dating and also themes brought from beyond the millennia; and indicate the ability of thought and speech of predecessors which have seen the world and its events with a careful and critical look and portrayed those issues with an eloquent verbal to the utmost brevity, and on the other hand, having multi-dimensional 
character and the ability to adapt to different situations in time and space, it has always been reliable and performed its role well in the area of cultural transmission with all its complex dimensions and in other words, duty or function that personal and social education of individuals have burdened on them. In next lines, some instances of personal and social functioning and sometimes a combination (personal/social) of proverbs are expressed.

\section{Personal function of proverbs:}

Some proverbs are merely recommendations that address the personal life of individuals in society and the individual can provide his own happiness by observing them- that represent common values and norms in that society- the following examples are instances of this type:

Visionary: "farseeing will not be followed by regret" (Rokhzady, 1382: 197, No. 125) = a man should keep his crib for a rainy day (Shakoorzadeh Boluri, 1380:16).

Self-esteem: "if I bully to my body, I won't beholden to knave" (Rokhzady, 1382: 326, No. $1)=$ the lion doesn't eat the remainder of dog's food (Shakoorzadeh Boluri, 1380:938).

Astute: "he drowns his enemy with sugar" Rokhzady, 1382: 194, No. 109) = a short man to the extent that is on the ground, twice of it is underground (Shakoorzadeh Boluri, 1380:25).

\section{Social function of proverb:}

Another group of proverbs is those which supervise social function and behavior of individuals of society as a member; and observing behaviors that were spoken by values and avoiding those that were blamed by proverbs and considered as anti-values will provide preparations for a good social life for people in that society.

Forgiveness: "manliness is in amnesty not revenge" (Rokhzady, 1382:117, No. 66) = forgive to be forgiven (Shakoorzadeh Boluri, 1380:510).

Eloquence: "you should have barely bread and wheaten mood" (Rokhzady, 1382:373, No. 23) = if you don't want bitter palate, be eloquent (Shakoorzadeh Boluri, 1380:829).

Not faultfinding: "he doesn't see shavings in his eyes, but hair in other's bite" (Rokhzady, 1382: 112, No. 34) = who is artless search for faults (Shakoorzadeh Boluri, 1380:1010).

Alliance: "if a man is supported by his brother, he won't be defeated unless by divine justice" (Rokhzady, 1382: 68, No. 50) = no sorrow for enemy's trick, because my friend is on my behalf (Shakoorzadeh Boluri, 1380:404).

\section{Combined function of proverb:}

The third category has an intermediate state that affects both personal and social life:

Harmful: "a black donkey is happy to die, provided that his owner will suffer losses" Rokhzady, 1382: 296, No. 103) = he eats his crop here and ovulates elsewhere (Shakoorzadeh Boluri, 1380:406).

Punishment of deed: "any tyrant has a decline" (Rokhzady, 1382: 413, No. 60) = don't dig a hole for someone, first you then someone else (Shakoorzadeh Boluri, 1380:405).

Seditious and sedition: "instead of shedding water on fire, he fans it (flares it) (Rokhzady, 1382: 82, No. 148) = a spark is the capital of global combustion (Shakoorzadeh Boluri, 1380:1028).

\section{Conclusion:}

Examining Kurdish proverbs will bring us some results that the following can be mentioned as some of them:

1. Proverbs include practical moral implications due to boiling language, thought and practical experiences of predecessors, and can be used and utilized practically in the work, effort and life scene. 
2. Examining the theme of proverbs indicates that they belong to two groups or particular category, in other words, proverbs can be classified in the two categories of positive proverb ( values and norms)and negative (anti-values and abnormalities) based on the message they transmit to the addressee. The first group strengthens positive ideas and actions for the society to turn to good behaviors, and the second group forbids indecent acts, acts that will have no result except corruption.

3. Proverbs have much capability in compliance with the spatial and temporal conditions in different periods and this issue is a very important factor for their reliability over time.

4. Based on function-oriented theory of Malinowski- which rests on needs- it can be concluded that the emergence of proverbs is the result of the society need in the distant past, the feeling that boiled within an intellectual person and flowed on his tongue; and has reminded the person about personal and social issues with a concise and clear language in order to provide a good life for everyone.

\section{Reference}

- Ahmadi, Ebrahim. (1386), A Dictionary Of Kenning, Sanandaj, Kurdistan University Press.

- Ahmadi, Ebrahim. (1389), A Dictionary Of puzzle and riddle In Kurdish, Kurdistan, college publications.

-Biro, Allen (1370), Culture, Social Sciences, translator Bagher Sarookhani ,Tehran, Kayhan, second edition.

- Coen, Bruce (1373), Principles of Sociology, Translated by Gholam Abbas Tavassoli and Reza Fazel, SAMT Press, Third Edition.

- Chalabi, Masoud. (1375), Sociological discipline: description and theoretical analysis of the social order, Tehran, Nai press.

- Fattahi Ghazi, Ghader (1364), Kurdish Proverbs (Part I), Tabriz, Tabriz University.

- Fattahi Ghazi, Ghader (1375), Kurdish Proverbs (Part II), Tabriz, Tabriz University.

- Hairat Sajjadi, Abdulhamid (1369), Pand-i Pishinyan, Salah aldin Ayoubi publication, Vol1.

- Hairat Sajjadi, Abdulhamid (1378), Pand-i Pishinyan, Salah aldin Ayoubi publication, Vol2.

- Islami Nadushan, Mohammad Ali (1387), culture and pseudo-culture, Tehran, Yazdan publication, Fourth Edition.

- Gidens, Anthony (1373), Sociology, translated by Manochehr Saboory. Tehran, Nai press.

-khal,Mohammad. (1971), Pand-i Pishinyan,Iraq, Baghdad, second edition.

- Mafakheri (Grdmyrany), Mohammad Kazem (1377), A collection of proverbs in different nations (Kurdish - Persian), Tehran, Saba Press.

- Maslow, Abraham. H., (1387), Religions, Values and Experience of the sublime,

Translated by Ali Akbar Shamloo, Agah press.

- Modarresi, Muhammad Aref (1384), Kalapori Kurdi, Sanandaj, Sheikhi trade book.

- Moein, Mohammad. (1379), A Persian dictionary, Tehran, Amir Kabir Publication Institute, Sixteenth Edition.

- Parsa, Ahmad. (1387), Comparative Study of Kurdish and Persian proverbs, Sanandaj, Kurdistan University publication.

- Rafee pour, Faramaz. (1378), Anatomy of Society: An Introduction to Applied Sociology,

Tehran, Company publication. 
- Rokhzady, Ali. (1382), Gwara-i kordawari, Sanandaj, publisher, author.

- Roche, Gay (1367), Social Action, translator Homa. Zanjanizadeh,Mashhad, Ferdowsi University of Mashhad.

- Sattari, Jalal. (1366),In the Realm of Culture, Tehran, Weiss press.

- Shakoorzadeh Boluri, Ebrahim.(1380),twelve thousand Persian's Proverbs, Mashhad, Beh Press Razavi Astan Quds publication, fourth edition.

- Talebi, A. (1380), "the religious symbols of religiosity among students and female students",Nama-e Pajohesh (20, 21), 77 to 96.

- VosoughiI, Mansour. (1370), Principles of Sociology, Tehran, Wise, second edition. 